\title{
Prevalence of Breastfeeding Practices Among Cuban Women in 2014
}

\author{
Santa Jiménez Acosta ${ }^{1}$, Ana Clúa Calderín ${ }^{2}$, María Elena Díaz Sánchez ${ }^{1}$, \\ Xiomara Podareda Valdés ${ }^{2}$ \\ ${ }^{1}$ National Institute of Higyene, Epidemiology and Microbiology, Havana, Cuba \\ ${ }^{2}$ National Division of Health Statistics, Ministry of Public Health, Havana, Cuba
}

Email address:

santa@inhem.sld.cu (S. J. Acosta)

\section{To cite this article:}

Santa Jiménez Acosta, Ana Clúa Calderín, María Elena Díaz Sánchez, Xiomara Podareda Valdés. Prevalence of Breastfeeding Practices Among Cuban Women in 2014. International Journal of Science and Qualitative Analysis. Vol. 3, No. 3, 2017, pp. 31-36. doi: $10.11648 /$ j.ijsqa.20170303.12

Received: August 2, 2016; Accepted: August 17, 2016; Published: December 4, 2017

\begin{abstract}
Introduction: Breastfeeding is the first measurement of nutrition and food security and considered to be a key element of infant health. The benefits of breastfeeding on the infant and maternal health are well documented in the literature. In Cuba the most recent survey was developed in 2014 and provides a document on indicators for assessing infant and young child feeding programs and strategies. Objective: To analyze the breastfeeding practices and associated factors among mothers of children less than 24 months in rural and urban areas of Cuba. Methods: A complex, stratified, multi-stage cluster sampling design was used. The questionnaire was administered to the mothers by trained personnel of different statistic division in the country and collected information on the general characteristics of the household, men and women between 15 to 49 years and children below five years. Information related to initiation of breastfeeding, exclusive breastfeeding for up to six months, and continuation of breastfeeding until 24 months of age, among others were recorded. Descriptive statistics were used to summarize the outcome variables and other variables of interest using the SPSS package version 21. Results: Most respondent have between 20-24 years age. The prevalence of exclusive breastfeeding was 33,2\% with a limit of confidence $95 \%$ between de 18-48, from 0 to 1 monththe prevalence of exclusive breastfeeding shows $93,3 \%$ but from 2 to 3 months this dropped sharply to $28,7 \%$. Data from this survey suggest that the biggest percent of mother who initiated breastfeeding within one hour of birth corresponded with the secondary level of education $(59,4 \%)$ while the biggest percent of mother who initiated breastfeeding in the first day after delivery was in correspondence with the university level. Conclusion: The prevalence of exclusive breastfeeding until 6 months of age in Cuba continues to be suboptimal, this findings indicate that is necessary to support breastfeeding and increases promotional activities.
\end{abstract}

Keywords: Breastfeeding, Exclusive Breastfeeding, Prevalence of Breastfeeding

\section{Introduction}

Breastfeeding is the first measurement of nutrition and food security and considered to be a key element of infant health. World Health Organization promotes exclusive breastfeeding until infants are six months old which has a great contribution in reducing infant mortality rate [1-2].

The benefits of breastfeeding on the infant and maternal health are well documented in the literature; it is speciesspecific and is associated with benefits to both mother and child. The child contribution includes a protective effect against gastrointestinal, respiratory and otherinfections. Long-term benefits to the breastfed child include a reduction in diabetes mellitusboth type 1 and type 2, and other illness in adult life [3-7].

However, the accuracy of some data about the breastfeeding are not clearin some publications because they report more data on predominant breastfeeding that on exclusive breastfeeding [8].

The practice of exclusive breastfeeding has been less than optimal in many developing countries including Cuba. In Cuba since 2001 the Ministry of Public Health and UNICEF have been carried out the Multiple Indicators Cluster Survey 
(MICS) regularly [9] the most recent survey was developed in 2014 and provides a document on indicators for assessing infant and young child feeding programs and strategies.

Present paper aims to analyze the breastfeeding practices and associated factors among mothers of children less than 24 months of age in rural and urban areas of Cuba.

\section{Materials and Methods}

This cross-sectional study was based on data of a large household survey (MICS) that took place in Cuba between February and September 2014 [10] to obtain information related to situation about children, women and men in the country and identify vulnerability in the application of different programs.

The survey was conducted by the National Division of Statistics of the Ministry of Public Health with support from UNICEF. Mothersor care providers of infant below five years ofage were interviewed face to face using MICS structured questionnaire adapted according Cuban population characteristic, questions about breastfeeding to mothers of children between 0 and 23 months of age were applied (n $=2320$ ).

\subsection{Sampling}

A complex, stratified, multi-stage cluster sampling design was used. The first stage of sampling was based on the statistic health system which has the list of population attended by family doctors and nurses office which cover almost the whole country, the lists are disaggregated by geographic region, and urban and rural area with actualization every year. It was the frame sampling for selection of Primary Units of Sampling (PUS). The selections on PUS were stratified by region and with probability rationale to size.

In the second stage of sampling in each health area (polyclinic) two offices of family doctorswere selected.

For the selection of the third stage, in each family doctor's office selected using thefamily clinical historywhich have information about all members of the family and their age, ten household without children below 5 years old and 15 with children of the same age were chosen.

The questionnaire was administered to the mothers by trained personnel of different statistic division in the country and collected information on the general characteristics of the household, men and women between 15 to 49 years and children below five years. Information related to initiation of breastfeeding, exclusive breastfeeding for up to six months, and continuation of breastfeeding until 24 months of age, among others were recorded.

\section{Training and Fieldwork}

Training for the fieldwork was conducted on three regional seminaries and 16 activities of training in the provinces. Each seminary had two modalities of performing: one with presence during six days and other on line. Total time for training was 18 days and 80 hours of preparation between November and December 2013. Training included lectures on interviewing techniques and the contents of the questionnaires, and mock interviews between trainees to gain practice in asking questions.

\subsection{Statistical Analysis}

All entry data was performed by different provinces, with a minimum of two operators; supervision was carried out for qualified personnel who further checked for correctness and consistency upon completion.

For quality assurance purposes, all questionnaires were double-entered and internal consistency checks were performed.

Descriptive statistics were used to summarize the outcome variables and other variables of interest using the SPSS package version 21 .

Four levels of education were recorded: none, primary (15 th grade), secondary (6-10th grade) technical and bachelor (until 12th grade) and university (college). Area of residence was categorized as rural and urban. 'Breastfeeding information' was recorded following the same scheme that MICS standards.

The calculated key indicatorsare explained below [9]:

Early initiation of breastfeeding: Proportion of women with a live birth in the last 2 years who put their last newborn to the breast within one hour of birth.

Exclusive breastfeeding under 6 months: Proportion of infants $0-5$ months of age who are fed exclusively with breast milk and not receiving any other fluids or foods, with the exception of oral rehydration solution, vitamins, mineral supplements and medicines during the previous day.

Continued breastfeeding at 1 year: Proportion of children 12-15 months of age who are fed breast milk.

Continued breastfeeding at 2 years: Proportion of children 20-23 months of age who are fed breast milk.

Predominant breastfeeding under 6 months: Proportion of infants $0-5$ months of age who received breast milk as the predominant source of nourishment ${ }^{1}$ during the previous day.

Duration of breastfeeding: Median duration of breastfeeding among children less than 36 months of age.

Bottle-feeding: Proportion of children 0-23 months of age who are fed with a bottle.

The study was approved by the Human Research Ethics Committee of the Ministry of Health.

\section{Results}

Table 1 summarizes the mothers' age in five categories between 15 to 49 years, most respondent have between 20-24 years $(32,1 \%)$ following by women from 25-29 years $(28,8 \%), 8.0 \%$ of mothers were adolescents.

Majority of the mother were in a married or common-law relationship (79,3\%), 16,2\% were divorced, and only $4,6 \%$ never married.

Table 2 shows the practices of exclusive breastfeeding according to residence area and sex. $31 \%$ of males and $35 \%$ of females were exclusive breastfed, $29,6 \%$ were living in urban areas and $45,4 \%$ in rural areas. The prevalence of 
exclusive breastfeeding was $33,2 \%$ with a limit of confidence $95 \%$ between de $18-48 \%$, in 540 infant aged less than 6 months during the study.

Table 1. Age categories of the mother or caregiver. Cuba 2014.

\begin{tabular}{lll}
\hline Age & Frequency & \% \\
\hline $15-19$ & 185 & 8.1 \\
$20-24$ & 739 & 32.1 \\
$25-29$ & 663 & 28.8 \\
$30-34$ & 442 & 19.2 \\
$35-49$ & 271 & 11.8 \\
Total & 2301 & 100.0 \\
\hline
\end{tabular}

Table 2. Prevalence of exclusive breastfeeding practices according to sex and residence area. Cuba 2014.

\begin{tabular}{lll}
\hline Exclusive breastfeeding under six months & n & \% \\
\hline Male & 243 & 31.0 \\
Female & 297 & 35.0 \\
Urban area & 418 & 29.6 \\
Rural area & 122 & 45.4 \\
Cuba & 540 & 33.2 \\
\hline
\end{tabular}

Figure 1 shows maternal education status and time of initiation of breastfeeding, 47,9\% ofmothers told having put their infants to the breast within one hour of birth but the majority of them reported to have started breastfeeding within the first dayafter delivery. Data from this survey suggest that the biggest percent of mother who initiated breastfeeding within one hour of birth corresponded with the secondary level of education $(59,4 \%)$ while the biggest percent of mother who initiated breastfeeding in the first day after delivery was in correspondence with the university level $(86 \%)$.

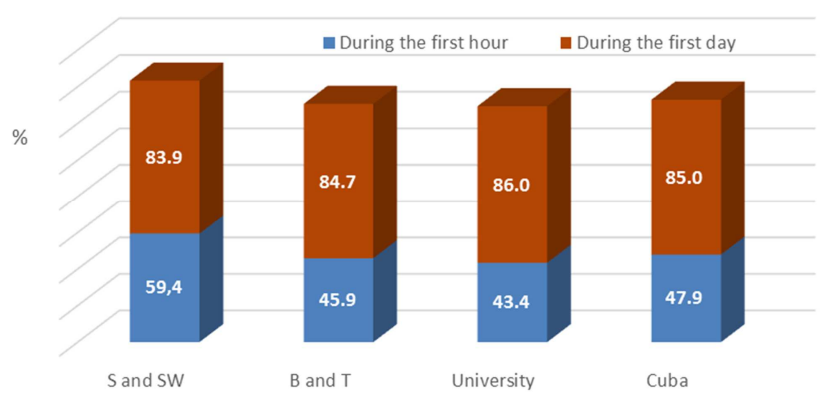

Fig. 1. Initiation of breastfeeding according to education level of the mothers.

Legend: S: Secondary; SW: Skilled Worker; B: Bachelor; T: Technician Source: MICS 2014

Regarding the place of residence nearly $55,3 \%$ of the mothers who initiated breastfeeding during the first hour after birth come from rural areas. Initiating breastfeeding within the first day after delivery was also higher in rural area (figure 2).

Table 3 displays the median duration of exclusive and predominant breastfeeding it was 2.0 and 2.2 months respectively. Similar data was obtained according to the newborn sex in both categories. Median duration in urban area was lowest than in rural area (2,0 vs. 2,9 months). Mothers with education level of bachelor shows the biggest median duration of exclusive breastfeeding.

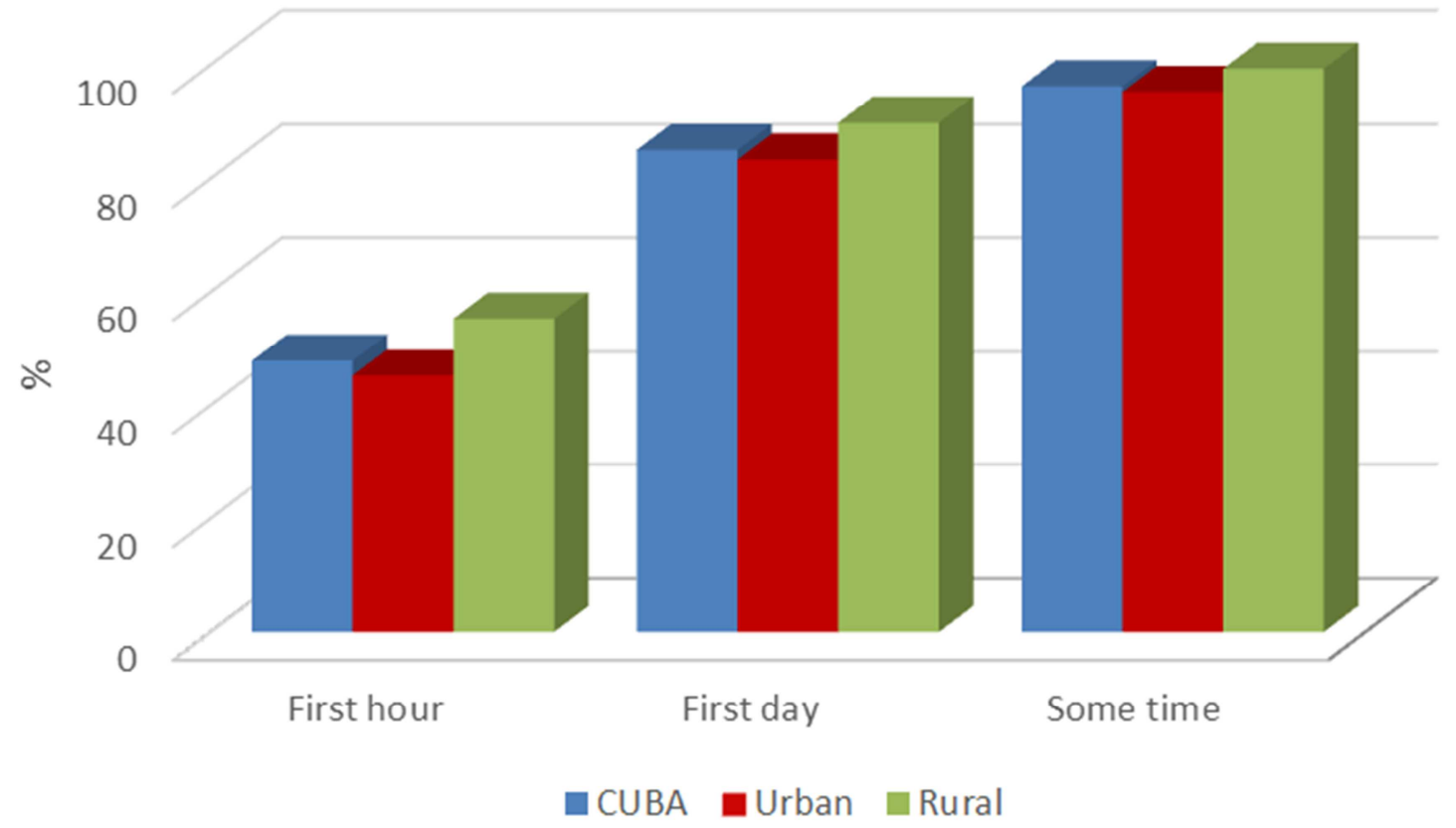

Source: MICS 2014

Fig. 2. Iniciation of breastfeeding in Cuba, urban and rural areas.

Figure 3 revealed that $39, \%$ of the mothers reported the prolongation of breastfeeding during one year and $24.0 \%$ maintained this practices until 2 yearsage of their babies. The percentage in female babies was much higher than in male. If we appreciate the comparison between surveys took place in 2010-11 and data from 2014 is easy to note the increase in prevalence in two categories mainly in rural areas in 2014. 


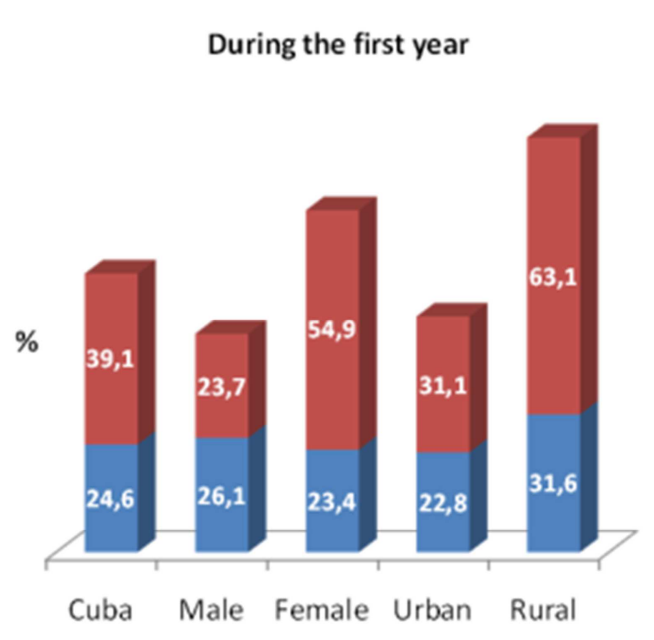

= 2014

$\square 2011$
Until the second year

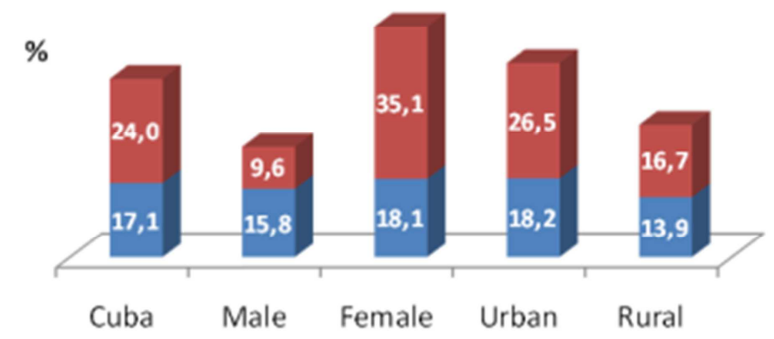

Source: MICS 2014

Fig. 3. Prolongation of breastfeeding through the first year and up to the second year.

Table 3. Median duration of exclusive and predominant breastfeeding. Cuba 2014.

\begin{tabular}{lll}
\hline Variables & Median duration (months) & \\
\hline Sex & Exclusive breastfeeding & Predominant breastfeeding \\
Female & 2.0 & 2.1 \\
Male & 2.1 & 2.2 \\
Residence area & & \\
Urban & 1.9 & 2.0 \\
Rural & 2.4 & 2.9 \\
Education level & & \\
Primary or none & - & - \\
Secondary & 1.8 & 1.9 \\
Bachelor & 2.1 & 2.3 \\
College & 1.9 & 2.1 \\
Total & 2.0 & 2.2 \\
\hline
\end{tabular}

Food patterns of infant for intervals of age between 0-23 months evidencedthat from 0 to 1 monththe prevalence of exclusive breastfeeding shows $93,3 \%$ but from 2 to 3 months this dropped sharply to $28,7 \%, 32,4 \%$ of infant not breastfed at this age but receive cow milk or another milk formula (table 4). 5,5\% of the children were given breastfeeding plus water or other liquids between 2-3 months. 55\% of children used breastfeeding plus complementary feeding since four months.

Table 4. Feeding patterns in children from 0 to 23 months. Cuba 2014.

\begin{tabular}{|c|c|c|c|c|c|c|c|c|}
\hline Age & $\begin{array}{l}\text { Exclusive } \\
\text { Breastfeeding }\end{array}$ & $\begin{array}{l}\text { Breastfeeding }+ \\
\text { water }\end{array}$ & $\begin{array}{l}\text { Breastfeeding+ } \\
\text { other liquids }\end{array}$ & $\begin{array}{l}\text { Breastfeeding+ other } \\
\text { milk formula }\end{array}$ & $\begin{array}{l}\text { Breastfeeding+ } \\
\text { complementary feeding }\end{array}$ & $\begin{array}{l}\text { NO } \\
\text { breastfed }\end{array}$ & Total & $\begin{array}{l}\text { No. of } \\
\text { child }\end{array}$ \\
\hline $0-1$ & 93.3 & 1.5 & 0.0 & 4.7 & 0.0 & 0.5 & 100 & 111 \\
\hline $2-3$ & 28.7 & 4.7 & 0.8 & 29.1 & 4.2 & 32.4 & 100 & 199 \\
\hline $4-5$ & 8.0 & 3.3 & 5.4 & 10.7 & 55.0 & 17.5 & 100 & 230 \\
\hline $6-7$ & 1.7 & 7.8 & 0.2 & 2.1 & 59.2 & 29.0 & 100 & 215 \\
\hline $8-9$ & 0.0 & 0.0 & 0.0 & 0.0 & 64.6 & 35.4 & 100 & 190 \\
\hline $10-11$ & 0.4 & 0.0 & 0.3 & 0.0 & 37.6 & 61.7 & 100 & 227 \\
\hline $14-15$ & 0.0 & 0.0 & 0.0 & 0.0 & 27.8 & 72.2 & 100 & 180 \\
\hline $16-17$ & 0.0 & 0.0 & 0.0 & 0.0 & 21.9 & 78.1 & 100 & 222 \\
\hline $18-19$ & 0.0 & 0.0 & 0.0 & 0.0 & 36.1 & 63.9 & 100 & 218 \\
\hline $20-21$ & 0.0 & 0.0 & 0.0 & 0.0 & 30.2 & 69.8 & 100 & 157 \\
\hline $22-23$ & 0.0 & 0.0 & 0.0 & 0.0 & 18.6 & 81.4 & 100 & 185 \\
\hline
\end{tabular}

\section{Discussion}

In this study majority of women have below 30 years age and $8 \%$ were adolescents.

Exclusive breastfeeding for the first six months is identified as the first intervention for food and nutritional security and one of intervention to reduce the infant mortality rate, because children have a much lower risk of infectious diseases than infant who received other milk formulas [11].

In this study, the rate of exclusive breastfeeding for six month was found to be $33,2 \%$ lower than data reported in 
another study in 2010-11 with the same methodology where exclusive breastfeeding was 48,2\% [12] showing a decreaserates of exclusive breastfeeding. This could be due in part to lack of enough knowledge on the protective effects of exclusive breastfeeding, comprehensive lactation support which includes family and ensuring that new mothers receive adequate information in a timely manner. In that sense is better to know what type of information mothers felt has not been provided and which would have found helpful for breastfeeding.

In the other hand all women in Cuba receive protection of maternity and childhood from the state by "Working Women's Maternity Law" and granted a subsidy in cash to working mother in the first year after de baby born. This law ensures a good opportunity for improve breastfeeding.

As has been recommended by Black et al [13] breastfeeding indicators in Cuba are included in national program of maternal and child care and in nutrition action plan. Considering the value as measurement for food security.

In Canada in 2011-2012 according to the Canadian Community Health Survey [14], 26\% of mothers breastfeed exclusively for six months or more. In United State of America [15] the prevalence is $17 \%$ and in Australia [16] the prevalence is lower $(15 \%)$. With the questionnaire used in this study was not possible to ask women about why they stopped breastfeeding or the breastfeeding support. Efforts have been made to promote and support breastfeeding in Cuba but it is needed to explore the barriers and the challenges faced by breastfeeding mothers. Cuba had implemented severalstrategies including the extension of the Baby Friendly Hospital in the provinces, the promotion of Baby Friendly policlinics and medical doctors office, the implementation of the International Code of the Marketing of Breast Milk Substitutes, other alternatives such as human milk banks andseveral interventions of education and communication, however, the proportion of women who exclusively breastfeed their babies up to six months remains low andbreastfeeding begins to decline once mother and baby return home.

In the present study $47,9 \%$ of women initiated breastfeeding lhour after birth whereas according several studies this percentage found in Cuba is higher than data reported by the National family survey in Karnataka [17] where the national average of mothers who had initiatedbreastfeeding within 1 hourwas $23.4 \%$ Another study carried out by Ranjana et al [18] showed that $20 \%$ of women put infants to breast within the first hour. However, the early time window of feeding within the first hour after birth is still weak. Thepercentage of women who initiated breastfeeding their newborn baby after 24 hours is also higher in our findings $(85 \%)$ compared with the studies mentioned above, mother with higher level of education showed the best rates of initiation of breastfeeding in the first 24 hours. In Cuba close to $100 \%$ of deliveries are professionally attended and this offers a good possibility for increases this figure.

Systematic reviews [19] suggest breastfeeding initiation within 24 hours of birth is associated with $44-45 \%$ reduction in all cause of infection related neonatal mortality.

The Lancet Series on Maternal and Child Under nutrition 2 [20], indicated that global progress on promotion of breastfeeding and support strategies is both uneven and suboptimum.

The current study evidenced that at 1 month almost all infant $(93.3 \%)$ have been breastfed but from 2-3 months declined markedly $(28,7 \%)$ and babies received prelacteal feeds or complementary feeding. Lactation counseling sessions to pregnant women in health facilities and community level could be increased.

More researches are necessary to conduct in an attempt to uncover the reason why so many mothers discontinued breast feeding prior to six month but we know to obtain life-long data in national survey would require cost and extra effort.

\section{Limitation}

As data from MICSwe used, applied methodology and recorded variables do not permit other kind of analysis especially founding barriers to breastfeeding and relationship with duration of breastfeeding.

\section{Conclusion}

The prevalence of exclusive breastfeeding until 6 months old in Cuba is $33,2 \%$ in 2014, and continues to be suboptimal, this findings indicate that is necessary to deep breastfeeding support and promotional activities.

\section{Acknowledgement}

The authors would like to thank the UNICEF and are grateful to all personnel who participated in the different stages of the study.

\section{References}

[1] WHO. Global Strategy for Infant and Young Child Feeding: World Health Organization and UNICEF. Geneva: WHO; 2003.

[2] WHO. The Optimal Duration of Exclusive Breastfeeding: A Systematic Review. Geneva: WHO; 2002.

[3] Horta BL, Victora CG. Long-term effects of breastfeeding: A systematic review. World Health Organization, 2013. [cited 20 march 2016] Available on: http://www.who.int/maternal_child_adolescent/documents/ 9241595230/en/.

[4] National Health and Medical Research Council. Infant Feeding Guidelines. Canberra: National Health and Medical Research Council, 2012.[cited 15 February 2016]Available on:

http://www.nhmrc.gov.au/ files nhmrc/publications/attachme nts/n56b_infant_feeding_guideline_summary.pdf.

[5] Brand E, Kothari C, Stark MA. Factors related to breastfeeding discontinuation between hospital discharge and 2 weeks postpartum. J Perinat Educ. 2011; 20:36-44. 
[6] Guo S, Fu X, Scherpbier RW, Wang Y, Zhou H, Wang X, et al. Breastfeeding rates in central and western China in 2010: implications for child and population health. Bull World Health Organ. 2013;91: 322-31.

[7] Gartner LM, Morton J, Lawrence RA, Naylor AJ, O'Hare D, Schanler RJ, et al. Breastfeeding and the use of human milk. Pediatrics. 2005; 115: 496-506.

[8] Jiang JX, Lin LM, Lian GL, Greiner T: Vitamin A deficiency and child feeding in Beijing and Guizhou, China. World J Pediatr 2008, 4: 20-25.

[9] Multiple Indicator Cluster Survey (MICS) [cited 18 February 2016]. Available on: www.unicef.org/statistics/index_24302.html.

[10] Cuba. Encuesta de Indicadores Multiples por Conglomerados 2014. [cited 16 February 2016]. Available on: http://files.sld.cu/dne/files/2015/09/mics5-2014-cuba.pdf.

[11] LadomenouF, Moschandreas J, Kafatos A, Tselentis Y, GalanakisE. Protective effect of exclusive breastfeeding against infections during infancy: a prospective study. Arch Dis Child. 2010; 95 (12): 1004-1008.

[12] Dirección Nacional de Registros Médicos y Estadísticas de Salud/UNICEF. Encuesta de Indicadores Múltiples por Conglomerados 2010/11. Cuba. La Habana 2012.

[13] Black RE, Victora CG, Walker SP, Bhutta ZA, Christian P, de Onis $M$, et al. Maternal and child undernutrition and overweight in low-income and middle-income countries. Lancet. 2013; 382: 427-5.
[14] Gionet L. Breastfeeding trends in Canada. Statistics Canada Catalogue no. (number) 82-624x. [cited 23 march 2016] Available from: http//www.statcan,gc.ca/pub/82624/2013001/article/11879-eng.htm.

[15] National Center for Chronic Disease Prevention and Health Promotion. Breastfeeding report card United States 2013. Atlanta. Center for Disease Control and Prevention; 2013.

[16] Australian Institute of Health and Welfare. Australia's Health 2012. Australia's Health Series No. 13 Cat No. AUS156. Canberra. Australia Institute of Health and Welfare; 2012.

[17] National Family Health Survey (NFHS-3) Factsheets 20052006. [cited 22 march 2016] Available on: http://mohfw.nic.in/nfhsfactsheet.htm)

[18] Ranjana F, Lakshminarayana J, Ramnath T, Singh Madhu B. Health and nutritional status infant feeding practices of working women in Jodhpur city. Ann Arid Zone 2002; 41: 183-189.

[19] Debes AK, Kohli A, Walker N, Edmond K, Mullany LC. Time to initiation of breastfeeding and neonatal mortality and morbidity: a systematic review. BMC Public Health [cited28 march 2016] Available on: $\mathrm{http} / / / \mathrm{bmcpublichealth.biomedcentral.com/articles/10.1186/14}$ 71-2458-13S3-S19.

[20] Cai X WT, Brown DW. Global trends in exclusive breastfeeding. Int Breastfeed J 2012; 7: 12-14. 